\title{
Investigation of Extraction and Purification Technology of Total Saponins from Sindora glabra Seeds
}

\author{
Yiping Chen ${ }^{\mathrm{a}}$, Chen Chen ${ }^{\mathrm{b}}$, Zhenyi Liang ${ }^{\mathrm{c}^{*}}$, Bo Wang ${ }^{\mathrm{d}}$ and Pinghuai Liu ${ }^{\mathrm{e}}$
}

Key Laboratory of Ministry of Education for Advanced Materials in Tropical Island Resources, School of Material \& Chemical Engineering of Hainan University, Haikou 570228, P. R. China

achen-yiping@tom.com, b276676255@qq.com, cliangzhenyi@163.com, dwangbo@hainu.edu.cn, etwlph@163.com

\begin{abstract}
Keywords: Sindora glabra seeds, Total saponins, Extraction process, Orthogonal experiments.
Abstract. Ginsenoside Re is employed as the reference substance for the determination of contents, elution rate of the total saponins from Sindora glabra seeds is as the evaluation index, the optimum extraction technology derives from the $\mathrm{L}_{9}\left(3^{4}\right)$ orthogonal experiments designed for purpose of the maximum extraction of total saponins. The results showed that the optimum extraction process is: concentration of ethanol $70 \%(\mathrm{v} / \mathrm{v})$, temperature for extraction $50^{\circ} \mathrm{C}$, ratio of crude materials to liquid $1: 15$, time $2.5 \mathrm{~h}, \mathrm{XAD}$ resin is employed to extract the desired substrates total saponins, flow rate $1.0 \mathrm{~mL} / \mathrm{min}$, desorption first by $6 \mathrm{bv}$ distilled water, followed by ethanol $7 \mathrm{BV} 70 \%$. The adsorption capacity of XAD macroporous resin on the total saponins is proved to be large and easy to be desorption.
\end{abstract}

\section{Introduction}

Sindora glabra Merr. Ex de Wit is widely used in tropics areas with high economical values [1]. It is a large tree mainly distributed in Southeast Asia, Hainan island of China and other tropical and subtropical regions [2]. Sindora glabra is rich in oil, similar to the flammability of diesel, and so is called "diesel tree". Currently, research on S. glabra is limited to its resin oil [3-5]. Our research group studied the chemical compositions of $S$. glabra seeds. It was found that it is high in total saponins, which is considered to bear anti-inflammatory, analgesic and anti-tumor effects [6,7]. In this paper, orthogonal test, separation and purification with macroporous adsorption resin, were applied to extract and purify total saponins.

\section{Experimental}

All chemicals and solvents were of analytical grade and commercially available, and used without any purification. S. glabra seeds were collected in a mountain in mid Hainan Island and identified by Dazhou Li, senior engineer, from Hainan Forestry Science Institute. The seeds were kept in Key Laboratory of Ministry of Education for Advanced Materials in Tropical Island Resources.

\section{Analysis of the content in S. glabra seed}

Preprocess of the seed: $S$. glabra seeds were mill crushed into powder, packed in a dry bag and spared. A curtained amount of powder was taken, which was then introduced into petroleum ether (60 90), ultrasonicated and filted to discard petroleum ether liquid, repeated 3 to 4 times, filtering, remove solvents, and spared after drying as degreased seed powder. Set aside.

Samples preparations: $1.0 \mathrm{~g}$ the seed powder was placed in a round bottom flask, and ethanol was then introduced, refluxed, centrifuged, and the supernatant was collected and dried over a water bath, and then distilled water was used to dissolve. After that, the residues were defatted with ether, and water saturated n-butanol was employed to repeatly extract 3 times. The organic solvents were combined and dried, and methanol was added to dissolve until to a final $10 \mathrm{~mL}$. 
Preparation of reference solution: $5.0 \mathrm{mg}$ of ginsenoside Re was introduced into $50 \mathrm{~mL}$ volumetric flask, then methanol was added to dissolve, diluted, and shaked.

Determination of wavelength: A solution of $0.10 \mathrm{~mL}$ control sample was introduced into a $75 \mathrm{~mL}$ evaporation dish, remove water over a water bath. A fresh vanillin glacial and acetic acid solution of $5 \%, 0.2 \mathrm{~mL}$, and a solution of perchloric acid $0.8 \mathrm{~mL}$ were combined together, heated to $60^{\circ} \mathrm{C}$ for $15 \mathrm{~min}$, and then cooled over an ice-water bath for $5 \mathrm{~min}$, an additional $5 \mathrm{ml}$ of acetic acid was then added to the final control sample. Which was then canned, and at the wavelength of 550nm it was found a maximum absorption.

Calibration: Sample solutions of $0.00 \mathrm{mg} / \mathrm{mL}, 0.10 \mathrm{mg} / \mathrm{mL}, 0.20 \mathrm{mg} / \mathrm{mL}, 0.40 \mathrm{mg} / \mathrm{mL}, 0.60$ $\mathrm{mg} / \mathrm{mL}$, and $0.80 \mathrm{mg} / \mathrm{mL}$ were well prepared, and samples of $2 \mathrm{~mL}$ of the corresponding solutions were taken, the water was removed and the residues were introduced to a combination of $0.2 \mathrm{~mL}$ of fresh solution of vanillin glacial and acetic acid and $0.8 \mathrm{~mL}$ of solution of perchlorate, the mixtures were then heated to $60^{\circ} \mathrm{C}$ for $15 \mathrm{~min}$, cooled with ice bath for $5 \mathrm{~min}$, and additional $5 \mathrm{~mL}$ of ice acetic acid were added to the corresponding solution to form final solutions. The calibration equation is: $\mathrm{A}=0.8185 \mathrm{x}+0.0152, R^{2}=0.9968$. It was indicated that the calibration has a good linear correlation.

Verification: The experimental results showed that the average content of total saponins was $4.33 \%$ and RSD was $2.12 \%$, and the extraction process has a good repetition.

\section{Results and discussion}

\section{Extraction technology of total saponins of S. glabra seed [8]}

Through pre-experiments, ethanol was chosen as the solvent for extraction and purification, for purpose of an optimized extraction conditions, concentration of ethanol (A), temperatures (B), ratio of solid to liquid (C) and extraction times (D) were as the possible factors for the determination of the content of total saponins, orthogonal test of $\mathrm{L}_{9}\left(3^{4}\right)$ were carried out. The results are listed in table 1 .

Table 1 Orthogonal results

\begin{tabular}{|c|c|c|c|c|c|}
\hline \multirow{2}{*}{ Entry } & \multicolumn{4}{|c|}{ Factor } & \multirow{2}{*}{ Absorption } \\
\hline & $\mathrm{A}[\%]$ & $\mathrm{B}\left[{ }^{\circ} \mathrm{C}\right]$ & $\mathrm{C}[\mathrm{m}: \mathrm{v}]$ & $\mathrm{D}[\mathrm{h}]$ & \\
\hline 1 & 60 & 50 & $1: 10$ & 1 & 1.017 \\
\hline 2 & 60 & 60 & $1: 15$ & 2 & 0.568 \\
\hline 3 & 60 & 70 & $1: 20$ & 2.5 & 0.717 \\
\hline 4 & 70 & 50 & $1: 15$ & 2.5 & 2.117 \\
\hline 5 & 70 & 60 & $1: 20$ & 1 & 0.553 \\
\hline 6 & 70 & 70 & $1: 10$ & 2 & 0.524 \\
\hline 7 & 80 & 50 & $1: 20$ & 2 & 2.062 \\
\hline 8 & 80 & 60 & $1: 10$ & 2.5 & 1.276 \\
\hline 9 & 80 & 70 & $1: 15$ & 1 & 1.039 \\
\hline K1 & 0.767 & 1.732 & 0.939 & 0.870 & \\
\hline $\mathrm{K} 2$ & 1.065 & 0.799 & 1.241 & 1.051 & \\
\hline K3 & 1.459 & 0.760 & 1.111 & 1.370 & \\
\hline $\mathrm{R}$ & 0.692 & 0.972 & 0.302 & 0.500 & \\
\hline
\end{tabular}

Results in Table 1 indicated that, the optimized extraction condition is: concentration of ethanol, $70 \%$, extraction temperature, $50 \mathrm{oC}$, ratio of solid to liquid, $1: 15$, and soaking time, $2.5 \mathrm{~h}$. A total of $4.29 \%$ of total saponins could be extracted from $S$. glabra seeds.

\section{Purification of macroporous resin}

Saturated adsorption determination. Samples of $10 \mathrm{mg} / \mathrm{mL}$ of extraction solution from $S$. glabra seeds were dealed with columns filled with $8 \mathrm{~mL}$ XAD resin, 8 collections were collected and determined the absorption, and the results were listed in Table 2. 
Table 2 Determination of saturated adsorption

\begin{tabular}{ccccccccc}
\hline BV & 1 & 2 & 3 & 4 & 5 & 6 & 7 & 8 \\
Absorption & 0.014 & 0.128 & 0.348 & 0.480 & 0.636 & 0.659 & 0.671 & 0.673 \\
\hline
\end{tabular}

Results in Table 2 indicated that with increased samples, a increase in absorbance could be observed, nevertheless, after collection 5, no obvious absorbance could be detected. Which means that the absorbance comes to saturation after acceptation of $10 \mathrm{~mL}$ collections. Therefore $10 \mathrm{~mL}$ collections proved to be the maximum absorption for the employed $8 \mathrm{~mL}$ XAD resin.

Screening for elution solvent. 3BV of extraction solution of $10 \mathrm{mg} / \mathrm{mL}$ from $S$. glabra seeds were subjected to go through a column filled with $8 \mathrm{~mL}$ XAD resin, repeated 3 times. And washed with 6BV distilled water, eluted with 2BV elution solutions ethanol of 30\%, 40\%, 50\%, 70\%, 90\%, respectively. One sample collection was made every $1 \mathrm{BV}$, there are 16 collections in total, whose absorptions were measured and the results were listed in Table 3.

Table 3 Choice of the elutions

\begin{tabular}{ccccccccc}
\hline BV & 1 & 2 & 3 & 4 & 5 & 6 & 7 & 8 \\
\hline Absorption & 1.439 & 0.538 & 0.431 & 0.201 & 0.128 & 0.016 & 1.078 & 0.249 \\
\hline BV & 9 & 10 & 11 & 12 & 13 & 14 & 15 & 16 \\
\hline Absorption & 1.089 & 0.249 & 0.105 & 0.133 & 2.438 & 1.951 & 1.508 & 0.864 \\
\hline
\end{tabular}

Results in Table 3 showed that when 6BV elution solutions were carried out, almost no absorption could be detected. The amount of elution was changed with increased elution solution, and when ethanol of $50 \%$ was used, the amount of elution became to be the smallest among all elution solutions tested, which proved to be the largest in elution amount when ethanol of $70 \%$ was employed.

Volume of employed elution solution. 3BV of extraction solution of $10 \mathrm{mg} / \mathrm{mL}$ from S. glabra seed were subjected to go through a column filled with $8 \mathrm{~mL}$ XAD resin, washed with $6 \mathrm{BV}$ distilled water, and eluted with $8 \mathrm{BV}$ ethanol solution of $70 \%$, one sample was collected every $1 \mathrm{BV}$, totally 8 ones were collected, the absorptions were measured and the results were listed in Table 4.

Table 4 Amount of ethanol of $70 \%$

\begin{tabular}{ccccccccc}
\hline BV & 1 & 2 & 3 & 4 & 5 & 6 & 7 & 8 \\
\hline Absorption & 2.276 & 1.812 & 1.006 & 0.476 & 0.227 & 0.163 & 0.102 & 0.041 \\
\hline
\end{tabular}

Results in Table 4 indicated that after the eighth collection, the absorption decreased sharply, which means that the concentration of total saponins in the collection is very low, most of the total saponins was eluted. Therefore, 7BV of elution solution ethanol of $70 \%$ proves to be enough for desorption.

Effect of flow rate on absorption. Four samples of extraction solution $2 \mathrm{BV}$ equipped with 4 steles of $8 \mathrm{~mL}$ XAD resin, washed with $6 \mathrm{BV}$ distilled water, eluted with $1 \mathrm{BV}$ ethanol solution of $70 \%$, collected and measured the corresponding absorptions, and the results were listed in Table 5.

Table 5 Relation between the absorption and flow rate

\begin{tabular}{ccccc}
\hline Flow rate[mL/min] & 1.0 & 2.0 & 3.0 & 4.0 \\
\hline Absorption & 0.807 & 0.675 & 0.592 & 0.220 \\
\hline
\end{tabular}

Results in Table 5 indicated that XAD resin has better adsorption capacity with low flow velocity, and the adsorption capacity decreased when flow rate increased. For consideration of easy operation and producing rate, the flow rate of $1 \mathrm{~mL} / \mathrm{min}$ was thus chosen. 


\section{Conclusions}

In this work, the extraction process of total saponin from Sindora glabra seeds was subjected to orthogonal test. The optimized conditions are: ethanol concentration, $70 \%$, extraction temperature 60 ${ }^{\circ} \mathrm{C}$, soaking time, $2 \mathrm{~h}$, and the ratio of solid to liquid, $1: 15$. The extraction rate of crude saponins can be reached to $4.29 \%$.

Experimental results proved that the XAD macroporous resin performed better for absorption of total saponins, which is proved to have larger adsorption capacity, easy adsorption and desorption. The optimal conditions among all the tested ones are: being eluted with $1.0 \mathrm{~mL} / \mathrm{min}$ distilled water, and then eluted with $6 \mathrm{BV}$, and then $7 \mathrm{BV}$ ethanol of $70 \%$ was used to get the total saponins. The pure total saponins is obtained in the yield of $59.65 \%$, and the extraction rate was $2.56 \%$.

\section{Acknowledgements}

This work was financially supported by the Science Foundation of Hainan province for college (Hjkj2013-04), the Project for Upgrading the Overall Strength of Midwest Colleges in China.

We would thank Mr. Dazhou Li for identifying the plant seeds and providing some information on Sindora glabra.

\section{References}

[1] A. K. Hossain, P. A. Davies. Plant oils as fuels for compression ignition engines: A technical review and life-cycle analysis. Renewable Energy, 35 (2010) 1-13.

[2] Editorial Committee of Chinese Academy of Sciences for Flora of China. Flora of China (Vol. 39), Science Press, Beijing, China, 1988.

[3] B Y Lu, Y J Li, L T Mai, et al. Study on the volatile constituents of Sindora glabra oil. Chemistry and Industry of Forest Products, 2 (1982) 26-30. In Chinese.

[4] J CH Yang, G T Yin, Z M Wu, et al. Physical and chemical properties of the oleoresin of Sindora glabra in Jianfengling national nature forest reserve, Hainan island of China. SCIENTIA SILVAE SINICAE, 47 (2011) 21-27. In Chinese.

[5] A J Zhang, Zh Y Liang, Y P Chen, et al. Chemical constituents of the oleoresin of Sindora glabra. Chemical Analysis and Meterage, 3(2013) 33-35. In Chinese.

[6] N Barmo, T Akihisa, H Tokuda, et al. Anti-inflammatory and antitumor-promoting efects of the triterpenes from the leaves of Eribortryajapena, Biol Pharm Bull, 10(2005)1995-999.

[7] G R Waller, Yamasaki I. Saponins used in traditional and modern medicine. Advances in Experimantal Medicine and Biology, 8(1996)40.

[8] Q Xu, H F Wang, X Y Zhou, et al. The optimum extraction conditions of saponin from pseudostellaria heterophylla (Miq.) Pax. Chin Trad Herb Drugs, 9(2001)799-800. 